\title{
The Effect of Visceral Abdominal Fat Volume on Oxidative Stress and Proinflammatory Cytokines in Subjects with Normal Weight, Overweight and Obesity
}

This article was published in the following Dove Press journal:

Diabetes, Metabolic Syndrome and Obesity: Targets and Therapy

\section{Andrés García-Sánchez (D) Jorge Iván Gámez-Nava $\mathbb{D}$ Elodia Nataly Díaz-de la Cruz (D) Ernesto Germán Cardona-Muñoz (D) Itzel Nayar Becerra-Alvarado (D) Javier Alejandro Aceves-Aceves (D) Esther Nérida Sánchez-Rodríguez (D) Alejandra Guillermina Miranda-Díaz (I)}

Department of Physiology, University Health Sciences Centre, University of Guadalajara, Guadalajara, Jalisco, Mexico

\begin{abstract}
Purpose: The increase of visceral abdominal fat (VAF) and oxidative stress (OS) are independent predictors for cardiovascular risk. This study aimed to determine the association of VAF with proinflammatory cytokines, oxidants, antioxidants, and oxidative damage to DNA in subjects with normal weight, overweight, and obesity.

Patients and Methods: A cross-sectional study that included 21 men and 71 women who attended for a medical check-up was conducted. Dual-energy X-ray absorptiometry (DXA) was used to measure the VAF volume. ELISA and colorimetric techniques were used for chemical analysis.
\end{abstract}

Results: Low activity of superoxide dismutase (SOD) was found in overweight and obese subjects compared to the normal weight group $(p=0.005)$. In contrast, the activity of glutathione peroxidase (GPx) was higher in the overweight and obesity groups compared to the normal weight subjects $(p=0.017$ ). The total antioxidant capacity (TAC) was also increased in the overweight group compared to the normal weight group $(p=0.04)$. According to the volume of VAF, the levels of tumor necrosis factor alfa and interleukin 6 showed no differences between subjects with normal and high VAF. Subjects with high VAF show higher levels of 8 -isoprostans compared to normal VAF group $(p=0.039)$. Less concentration of 8-oxoguanineDNA-N-glycosylase-1 (hOGG1) was found in the high VAF group $(p=0.032)$ compared to the normal VAF subjects. VAF was positively correlated with lipoperoxides (LPO) ( $\mathrm{r}=0.27$, $p<0.05)$ and 8 -isoprostanes $(\mathrm{r}=0.25, p<0.05)$. We also found correlations between oxidative stress markers and anthropometric ratios for intra-abdominal fat. The waist-hip ratio was positively correlated with LPO $(\mathrm{r}=0.30, p<0.05)$ and TAC $(\mathrm{r}=0.24, p<0.05)$.

Conclusion: These findings suggest that the predominantly oxidative damage associated with VAF in overweight or obesity is lipoperoxidation and oxidative DNA damage. Alterations in endogenous antioxidant defenses may not be linked to the amount of VAF.

Keywords: oxidative stress, oxidative DNA damage, antioxidant enzymes, Lunar iDXA, visceral fat cutoff score

\section{Introduction}

Obesity is a multifactorial disease that involves environmental components linked to unhealthy lifestyles characterized by increased intake of high-energy foods that favor the gradual accumulation of adipose tissue. ${ }^{1}$ Obesity determines important repercussions in the appearance of chronic degenerative diseases, which affects the costs of medical care for the population. ${ }^{2}$
Correspondence: Alejandra Guillermina Miranda-Díaz

Department of Physiology, University Health Sciences Centre, University of Guadalajara, Guadalajara, Jalisco, Mexico Email kindalexI@outlook.com 
In Mexico, a progressive increase in obesity has been observed since $2000 .^{2}$ It was previously reported that $62 \%$ of Mexican adults are at least overweight. ${ }^{3}$ Adipose tissue is considered an important endocrine organ with high lipid storage capacity for systemic management of energy substrates. Excessive lipid loading produces adipocyte stress with the ability to cause adverse effects on obesity. ${ }^{4}$ High accumulation of visceral adipose fat (VAF) leads to visceral obesity and the release of proinflammatory cytokines. In addition, VAF associated with the development of metabolic disorders such as type 2 diabetes mellitus (T2DM), hypertension, cardiovascular disease, and other chronic diseases. Some inaccurate anthropometric measures are used to estimate visceral obesity, such as waistcircumference and waist-hip ratio. ${ }^{5-7}$ There are accurate methods to measure VAF, such as magnetic resonance imaging and computed tomography. However, both are expensive and produce prolonged radiation exposure. ${ }^{8}$ Dual-energy X-ray absorptiometry (DXA) is a useful imaging technique that offers a simple, fast, and accurate estimate of VAF mass and volume with low radiation exposure. $^{9}$

Oxidative stress (OS) links obesity with its associated complications. Dyslipidemia, low antioxidant defenses, increased proinflammatory molecules, and reactive oxygen species (ROS) favor OS production. ${ }^{10}$ ROS can damage the DNA chain. Oxidation of guanine forms 8-hydroxy-2'deoxyguanosine (8-OH-dG) or 8-oxo-7,8-dihydro-2'deoxyguanosine (8-oxodG). ${ }^{11}$ These base oxidations can lead to cellular damage. Guanine bases can be repaired under normal conditions by the enzyme oxo-guanine glycosylase (OGG1). ${ }^{12}$

An increase in lipoperoxidation (LPO), and 8-epiprostaglandin F2 (8-iso-PGF2 $\alpha$ ) products and their correlation with VAF in patients with metabolic syndrome front non-obese subjects have previously demonstrated. ${ }^{13-15}$

The main antioxidants that neutralize ROS are catalase, superoxide dismutase (SOD) and glutathione peroxidase (GPx). ${ }^{16,17}$ Recently, the inverse relationship of SOD enzyme activity with VAF in obese men was reported. ${ }^{18}$ However, the clinical behavior of antioxidant enzyme activity concerning VAF has not clarified. The objective of the study was to determine the association of VAF on the endogenous antioxidant activity, oxidative markers, and proinflammatory cytokines in subjects with normal weight, overweight, and obesity.

\section{Patients and Methods}

\section{Subjects and Anthropometric Measures}

Ninety-two adult subjects who attended at the University Clinic of the University Center of Health Sciences of the University of Guadalajara for a medical check-up were included. For each patient was measured height, weight, waist-hip ratio. Body mass index (BMI) calculated as; weight divided by the square of the height $\left(\mathrm{kg} / \mathrm{m}^{2}\right)$. Waist circumference was measured between the lower margin of the last palpable rib and the top of the iliac crest. Hip circumference was taken around the widest portion of the buttocks. Then, the waist-hip ratio was calculated. ${ }^{19}$ The study subjects were divided according to the criteria of the World Health Organization (WHO) for BMI in normal weight $\left(18.5-24.9 \mathrm{~kg} / \mathrm{m}^{2}\right)$, overweight $\left(25-29.9 \mathrm{~kg} / \mathrm{m}^{2}\right)$ and obesity $\left(\geq 30 \mathrm{~kg} / \mathrm{m}^{2}\right){ }^{20}$

Subjects with systolic blood pressure $\geq 130 \mathrm{mmHg}$ or diastolic blood pressure $>80 \mathrm{mmHg}$ were considered hypertensive. $^{21} \mathrm{~T} 2 \mathrm{DM}$ established as fasting plasma glucose $\geq 126 \mathrm{mg} / \mathrm{dL}^{22}$ Dyslipidemia was set as high triglycerides $(\geq 150 \mathrm{mg} / \mathrm{dL})$, low HDL cholesterol $(<40 \mathrm{mg} / \mathrm{dL})$ or high LDL cholesterol $(\geq 160 \mathrm{mg} / \mathrm{dL}) .{ }^{23}$ No maintenance therapy was excluded. Subjects that reported cerebrovascular disease, hepatitis, kidney disease, or those who were taking antioxidants were not included.

For each participant, $10 \mathrm{~mL}$ of $8 \mathrm{~h}$ fasting blood was taken, $5 \mathrm{~mL}$ with EDTA, and $5 \mathrm{~mL}$ in the dry tube. The blood sample was centrifuged at $3000 \mathrm{rpm}$ for $10 \mathrm{~min}$ at room temperature. The supernatant (serum, plasma) was stored at $-80^{\circ} \mathrm{C}$ until final processing.

\section{Visceral Abdominal Fat}

The volume of VAF was determined by dual-energy $x$-ray densitometry (DXA). The densitometer Lunar iDXA, GE Healthcare $^{\circledR}$, Madison, WI with CoreScan ${ }^{\circledR}$ (software version 16.0) was used. The subjects lay supine with arms and palms placed parallel to body one centimeter from thigh aligned. The legs were fully extended, taking care that the feet did not touch each other. The scanning and cuts of the regions of interest were adjusted manually according to the manufacturer's instructions. Visceral fat measurement was performed by subtracting subcutaneous adipose tissue from the android fat. The coefficient of variation using a phantom standard was $0.25 \%$. The same expert technician in DXA performed the scans. ${ }^{24}$ 


\section{Proinflammatory Cytokines}

TNF- $\alpha$ and IL6

ELISA kit 900-K25 and 900-K16 (Peprotech, Rocky Hill, NJ 08553, USA ${ }^{\circledR}$ ) were used to determine the TNF- $\alpha$ and IL-6, respectively. Both cytokines had a detection limit of $32 \mathrm{pg} / \mathrm{mL}$. The cytokine identification was made in $100 \mu \mathrm{L}$ of a plasma sample. The plate was read at a wavelength of $405 \mathrm{~nm}$ with correction set at $650 \mathrm{~nm}$. The TNF- $\alpha$ intraassay coefficient of variation (CV) was $2.1 \%$, and IL-6 intra-assay $\mathrm{CV}$ was $4.7 \%$.

\section{Oxidative Stress Markers Products of Lipoperoxidation}

The serum LPO was measured by using FR12 assay kit (Oxford Biomedical Research Inc., Oxford, MI, USA ${ }^{\circledR}$ ). Plasma samples treated with N-methyl-2-phenylindole were centrifuged at 12,791 rpm for $10 \mathrm{~min}$, and the supernatant was obtained. The supernatant was added to a microplate, and absorbance was measured at $586 \mathrm{~nm}$. The duplicate standard intra-assay CV was $6.4 \%$.

\section{8-Isoprostane}

Plasma samples were analyzed according to the competitive ELISA assay (ABCAM ab175819 ${ }^{\circledR}$ Cambridge, United Kingdom). A 96 well microplate pre-coated with a capture antibody for 8-Isoprostanes was used. The optical density was read at $450 \mathrm{~nm}$. The duplicate standard intra-assay CV was $4.1 \%$.

\section{Nitric Oxide (NO)}

Before the assay, plasma samples were deproteinized by the addition of zinc sulfate ( $6 \mathrm{mg}$ of zinc sulfate was added to $400 \mu \mathrm{L}$ of the sample), vortexed for one min and the samples were centrifuged at $10,000-\mathrm{x}$ for $10 \mathrm{~min}$ at $4^{\circ} \mathrm{C}$. For measure NO, the kit NB98, Oxford Biochemical, Oxford, MI, USA ${ }^{\circledR}$ was used. The colorimetric signal was read at $540 \mathrm{~nm}$. The duplicate standard intra-assay CV was $7.9 \%$.

\section{Antioxidants}

\section{Superoxide Dismutase}

The kit (SOD No. 706002, Cayman Chemical Company ${ }^{\circledR}$, USA). The serum samples were diluted 1:2 in sample buffer before the colorimetric assay. Color development was read at a wavelength of $440 \mathrm{~nm}$. The dilution factor was used to calculate the results. The duplicate standard intra-assay $\mathrm{CV}$ was $5.4 \%$.

\section{Glutathione Peroxidase}

It was used the assay kit GPx 703,102 (Cayman Chemical Company ${ }^{\circledR}$, USA). Plasma samples $(20 \mu \mathrm{L})$ were added to a microplate of 96 wells with $70 \mu \mathrm{L}$ of buffer, $50 \mu \mathrm{L}$ of glutathione and glutathione reductase mixture and $50 \mu \mathrm{L}$ of NADPH. The activity was obtained by measuring the absorbance decrease at $340 \mathrm{~nm}$ every min for $20 \mathrm{~min}$. The activity expressed as $\mathrm{nmol} / \mathrm{min} / \mathrm{mL}$. The duplicate of positive control intra-assay $\mathrm{CV}$ was $1.5 \%$.

\section{Catalase}

We used the commercial kit Catalase-520 from Bioxytech (OxisResearch $^{\mathrm{TM}}{ }^{\circledR}$ Foster City. USA). Erythrocyte lysate was obtained from whole blood collected in EDTA tube centrifuged at $2500 \mathrm{~g}$ for $5 \mathrm{~min}$. Erythrocyte lysate was washed three times with cold $0.9 \% \mathrm{NaCl}$ and diluted $1 / 400$ with deionized water. The colorimetric assay was performed, and coloration was read at $520 \mathrm{~nm}$. The duplicate standard intra-assay $\mathrm{CV}$ was $2.3 \%$.

\section{Total Antioxidant Capacity}

Total antioxidant capacity (TAC) quantification was done following the (Total Antioxidant Power Kit, No. TA02.090130, Oxford Biomedical Research ${ }^{\circledR}$ ). The serum samples and standards were diluted 1:40, and $200 \mu \mathrm{L}$ were placed in each well of a microplate. Concentration was expressed as $\mathrm{mM}$ equivalents of Trolox (an analog of vitamin E). The duplicate standard intra-assay CV was $5.7 \%$.

\section{Oxidative Damage to DNA and Repair 8-Hydroxy-2'-Deoxyguanosine}

The assay 8-hydroxy-2'-deoxyguanosine No. ab201734 Abcam $^{\circledR}$, Cambridge, United Kingdom, was used. This competitive ELISA assay was performed with $50 \mu \mathrm{L}$ of serum samples. The color signal measured at $450 \mathrm{~nm}$. The duplicate standard intra-assay CV was $6.9 \%$.

\section{8-Oxoguanine-DNA-N-Glycosylase-I}

We followed ELISA kit hOGG-1 MBS702793 (My BioSource $^{\circledR}$, San Diego, CA). The optical density was read at $450 \mathrm{~nm}$ with a correction set at $540 \mathrm{~nm}$ using. The duplicate standard intra-assay CV was $11.3 \%$. For every optical density measure, the Synergy ${ }^{\mathrm{TM}}$ HT multi-detection microplate reader (Bio-Tek, Winooski, VT, USA) was used.

\section{Statistical Analysis}

Anthropometric data were expressed as mean \pm SD or percentages. OS markers were expressed as mean \pm SEM. The Kolmogorov-Smirnov test was used to analyze 
the normality distribution of data. To analyze the differences between multiple groups for continuous variables, we used one way ANOVA or Kruskal-Wallis test with the post-hoc Dunn-Bonferroni test for pairwise comparison. The inter-group comparison was conducted with Student's $t$-test or Mann-Whitney $U$-test. For categorical variables, the difference between the groups was calculated with $\mathrm{Chi}^{2}$ test. Spearman correlation test was used to evaluate the relation between the OS markers and the body mass measurements. The cutoff point for VAF was obtained using a receiver operating characteristic (ROC) curve analysis. The sensitivity, specificity, area under the curve (AUC), and confidence interval (CI) were calculated for the components of metabolic disorder (hypertension, dyslipidemia, or T2DM). The score with the highest Younden's index (sensitivity + specificity-1) was considered the optimal cutoff score. Two-tailed $p \leq 0.05$ was considered statistically significant. SPSS for Windows version 20.0 (IBM SPSS statics Inc., Chicago, IL, USA) was used.

\section{Ethical Considerations}

The research complies with the ethical principles for medical research in human beings stipulated in the Declaration of Helsinki 64th General Assembly, Fortaleza, Brazil October 2013. In addition to adhering to the standards of Good Clinical Practices. All procedures were performed according to regulations stipulated in the General Health Legal Guidelines for Health Care Research in Mexico, 2nd Title, in Ethical Aspects for Research in Human Beings, Chapter 1, and Article 17. All patients gave and signed the informed consent form in the presence of signed witnesses. The Local Ethics and Research Committee from the Institute of Experimental and Clinical Therapeutics, Centro Universitario de Ciencias de la Salud, Universidad de Guadalajara (CEI/487/2019) approved the study.

\section{Results}

\section{Comparison Between BMI Groups}

Subjects included in this study were classified in normal weight, overweight, and obese subjects. The obesity group included all the subjects with $\geq 30 \mathrm{~kg} / \mathrm{m}^{2}$. Twenty-one men with $56 \pm 13$ years of age and seventy-one women of 57 \pm 10 years of age were included. The overall prevalence of dyslipidemia and T2DM was $30 \%$ and $16 \%$, respectively. VAF showed a progressive increase in overweight and obese subjects $(p<0.01)$. The waist-hip ratio was higher in the obese subjects compared with normal weight $(p=0.01)$. The prevalence of hypertension was significantly higher in over-weight
$(28 \%)$ and obesity (49\%) compared with normal weight $(p=0.02)$. Levels of TNF- $\alpha$ and IL-6 were similar between normal weight, overweight, and obesity. No significant differences were found in oxidants or oxidative damage to DNA. The activity of SOD was significantly decrease in overweight $(0.35 \pm 0.05 \mathrm{U} / \mathrm{mL})$ and obese subjects $(0.34$ $\pm 0.06 \mathrm{U} / \mathrm{mL})$ compared to normal weight $(0.50 \pm 0.04$ $\mathrm{U} / \mathrm{mL}, p=0.005)$. Contrary, the GPx activity was found increase in overweight $(2.41 \pm 0.33 \mathrm{nmol} / \mathrm{min} / \mathrm{mL})$ and obese subjects $(2.17 \pm 0.25 \mathrm{nmol} / \mathrm{min} / \mathrm{mL})$ compare to normal weight $(1.28 \pm 0.16 \mathrm{nmol} / \mathrm{min} / \mathrm{mL}, p=0.015)$. The total antioxidant capacity was also higher in overweight $(2.34$ $\pm 0.11 \mathrm{mM})$ compared to the normal weight subjects $(2.19$ $\pm 0.10 \mathrm{mM}, p=0.05$ ). Table 1

\section{Cutoff Score for High Visceral Abdominal Fat}

Table 2 shows the results of ROC analysis and the optimal cutoff score for cardio-metabolic risk factors. The VAF volume had the highest AUC for hypertension and the lowest for dyslipidemia. The AUC for hypertension also showed the highest combination of specificity and sensibility with a Younden's index of 0.45 . The optimal cutoff score for hypertension was $1658.50 \mathrm{~cm}^{3}$ of VAF.

\section{Clinical Characteristics Between Normal and High Visceral Abdominal Fat}

In Table 3, subjects were divided into normal VAF $\left(<1658.50 \mathrm{~cm}^{3}\right)$ and high VAF $\left(\geq 1658.50 \mathrm{~cm}^{3}\right)$. The high VAF subjects showed a significant prevalence of hypertension $(p<0.001)$ and T2DM $(p=0.02)$. No differences in dyslipidemia between normal vs high VAF was found. Contrary to that found in BMI, subjects with high VAF had increased levels of 8 -Isoprostane $30.85 \pm 3.79 \mathrm{pg} / \mathrm{mL}$ vs $21.70 \pm 1.02 \mathrm{pg} /$ $\mathrm{mL}$ in normal VAF $(p=0.039)$. Decreased concentration of hOGG1 $3.07 \pm 1.15 \mathrm{ng} / \mathrm{mL}$ in high VAF front $5.81 \pm 0.92 \mathrm{ng} /$ $\mathrm{mL}$ in normal VAF $(p=0.032)$ was found.

\section{Correlations}

The volume of VAF and BMI were correlated proportionately with 8 -Isoprostanes $(\mathrm{r}=0.249, p<0.05$ and $\mathrm{r}=0.261$, $p<0.05)$. The waist-hip index was correlated proportionally with LPO $(\mathrm{r}=0.274, p<0.05)$ and with TAC $(\mathrm{r}=0.244$, $p<0.05)$. LPO also was positively correlated with volume of $\operatorname{VAF}(\mathrm{r}=0.274, p<0.05)$. Age showed positive proportional correlation with 8 -OHdG $(\mathrm{r}=0.278, p<0.05)$ Table 4. 
Table I Demographic Data, Inflammatory Cytokines and Oxidative Status in Subjects with Normal Weight, Overweight and Obesity

\begin{tabular}{|c|c|c|c|c|}
\hline & Normal Weight & Overweight & Obesity & \multirow[t]{2}{*}{$P$} \\
\hline & $n-23$ & $n-36$ & $n-33$ & \\
\hline \multicolumn{5}{|l|}{ Gender } \\
\hline Men n (\%) & $5(21.7)$ & $7(19.4)$ & $9(27.3)$ & 0.73 \\
\hline Women n (\%) & $18(78.3)$ & $29(80.1)$ & $24(72.7)$ & \\
\hline Age years & $68.77 \pm 10.66$ & $55.03 \pm 10.66$ & $56.45 \pm 10.84$ & 0.32 \\
\hline Visceral abdominal fat $\mathrm{cm}^{3}$ & $777.09 \pm 472.36$ & $1270.92 \pm 47 \mid .15^{\mathrm{a}, \mathrm{b}}$ & $1988.59 \pm 47 \mid .57^{\mathrm{a}}$ & $<0.0 I^{*}$ \\
\hline Hypertension n (\%) & $3(13)$ & $10(28)$ & $16(49)$ & $0.02^{* * * *}$ \\
\hline Dyslipidemia n (\%) & $8(35)$ & $10(28)$ & $10(30)$ & 0.71 \\
\hline T2DM n (\%) & $3(13)$ & $5(14)$ & $7(2 I)$ & 0.68 \\
\hline Waist-hip ratio & $0.85 \pm 0.08$ & $0.88 \pm 0.08$ & $0.91 \pm 0.06^{\mathrm{a}}$ & $0.01 *$ \\
\hline \multicolumn{5}{|l|}{ Inflammatory Cytokines } \\
\hline TNF- $\alpha$ pg/mL & $866.86 \pm 153.95$ & $680.97 \pm 79.67$ & $694.44 \pm 86.06$ & 0.96 \\
\hline $\mathrm{IL}-6 \mathrm{pg} / \mathrm{mL}$ & $437.62 \pm 78.06$ & $920.09 \pm 253.77$ & $566.50 \pm|27.3|$ & 0.93 \\
\hline \multicolumn{5}{|l|}{ Oxidative Damage to DNA and Repair } \\
\hline 8-OHdG ng/mL & $43.93 \pm 10.12$ & $54.85 \pm 16.04$ & $153.32 \pm 54.46$ & 0.15 \\
\hline hOGGI ng/mL & $5.42 \pm 1.58$ & $4.89 \pm 1.13$ & $4.97 \pm 1.26$ & 0.82 \\
\hline \multicolumn{5}{|l|}{ Oxidants } \\
\hline LPO $\mu \mathrm{M}$ & $4.30 \pm 0.42$ & $3.58 \pm 0.23$ & $3.80 \pm 0.22$ & 0.18 \\
\hline 8-Isoprostane $\mathrm{pg} / \mathrm{mL}$ & $24.25 \pm 2.20$ & $20.81 \pm 1.22$ & $28.44 \pm 3.09$ & 0.27 \\
\hline Nitric oxide $\mu \mathrm{M}$ & $234.81 \pm 11.37$ & $238.28 \pm 10.09$ & $242.36 \pm 10.12$ & 0.74 \\
\hline \multicolumn{5}{|l|}{ Antioxidants } \\
\hline SOD U/mL & $0.50 \pm 0.04$ & $0.35 \pm 0.05^{\mathrm{a}}$ & $0.34 \pm 0.06^{\mathrm{a}}$ & $0.005^{* *}$ \\
\hline $\mathrm{GPx} \mathrm{nmol} / \mathrm{min} / \mathrm{mL}$ & $1.28 \pm 0.16$ & $2.4 I \pm 0.33^{\mathrm{a}}$ & $2.17 \pm 0.25^{\mathrm{a}}$ & $0.015^{* *}$ \\
\hline Total antioxidant capacity $\mathrm{mM}$ & $2.19 \pm 0.10$ & $2.34 \pm 0.11^{\mathrm{a}}$ & $2.28 \pm 0.09$ & $0.05 * *$ \\
\hline Catalase $\mathrm{mU} / \mathrm{mL}$ & $18.07 \pm 2.00$ & $|6.75 \pm 1.3|$ & $18.35 \pm 1.72$ & 0.46 \\
\hline
\end{tabular}

Notes: Values are mean \pm SD, SEM, or percentage. 'vs normal weight. ${ }^{b}$ vs obesity. ${ }^{* * *}$ Chi-square test, ${ }^{*}$ Student's $t$-test, ${ }^{* * K}$ Kruskal-Wallis test.

Abbreviations: T2DM, type 2 diabetes mellitus; TNF, tumor necrosis factor alpha; IL-6, interleukin 6; 8-OHdG, 8-hydroxy-2'-deoxyguanosine; hOGGI, human oxoguanine glycosylase; LPO, lipoperoxides; SOD, superoxide dismutase; GPx, glutathione peroxidase.

\section{Discussion}

The main findings of the present study show that OS is proportionally correlated with increase VAF volume, waist-hip ratio, and BMI in overweight and obesity. In addition, the activity of antioxidant enzymes was found altered in overweight and obese subjects.

It is estimated that the prevalence of overweight and obesity worldwide increased between 1980 and 2013 by $27.5 \%$ for adults and $47.1 \%$ for children. ${ }^{25}$
In Mexico, the prevalence of obese or overweight people reported in 2017 was $62 \%{ }^{3}$ Some authors showed that prevalence is expected to increase to $88 \%$ for men and $91 \%$ for women for $2050 .^{26}$ In the present study, we found $75 \%$ prevalence of overweight and obesity in women and $76 \%$ in men. Even though VAF accumulation is associated with cardiovascular risks, there are only a few data related to ranges of normal or high VAF volume. Some studies used computed

Table 2 Cutoff Points for Visceral Abdominal Fat by Metabolic Disorder Risk Factors

\begin{tabular}{|l|l|l|l|l|l|l|l|}
\hline & AUC & $\mathbf{9 5 \%} \mathbf{C I}$ & Cutoff $\left.\mathbf{( c m}^{\mathbf{3}}\right)$ & Sensitivity & Specificity & YI & $\mathbf{P}$ \\
\hline Hypertension & 0.74 & $0.63 ; 0.85$ & 1658.50 & 0.58 & 0.87 & 0.45 & $<0.00 I^{*}$ \\
T2DM & 0.67 & $0.53 ; 0.82$ & 1730.50 & 0.53 & 0.81 & 0.34 & $0.034^{*}$ \\
Dyslipidemia & 0.59 & $0.48 ; 0.73$ & 1212.00 & 0.70 & 0.53 & 0.23 & 0.15 \\
\hline
\end{tabular}

Note: *Significant for receiver operating characteristic (ROC) curve analysis.

Abbreviations: T2DM, type 2 diabetes mellitus; AUC, area under the curve; Cl, confidence interval; YI, Younden's index. 
Table 3 Clinical Characteristics in Normal and High Visceral Abdominal Fat

\begin{tabular}{|c|c|c|c|}
\hline & Normal VAF $\left(<1658.5 \mathrm{~cm}^{3}\right)$ & High VAF $\left(\geq 1658.5 \mathrm{~cm}^{3}\right)$ & p \\
\hline Age years & $55.97 \pm 10.70$ & $58.96 \pm 9.60$ & 0.30 \\
\hline \multicolumn{4}{|l|}{ Gender } \\
\hline Men n (\%) & $11(16.7)$ & $10(38.5)$ & $0.025^{* * * *}$ \\
\hline Women n (\%) & $55(83.3)$ & $16(61.5)$ & \\
\hline $\mathrm{BMI} \mathrm{kg} / \mathrm{m}^{2}$ & $26.89 \pm 3.83$ & $33.50 \pm 5.45$ & $<0.001 *$ \\
\hline Waits-hip ratio & $0.87 \pm 0.08$ & $0.92 \pm 0.52$ & $0.003^{*}$ \\
\hline Hypertension n (\%) & $12(18.2)$ & $18(69.2)$ & $<0.001^{* * * *}$ \\
\hline Dyslipidemia n (\%) & $19(28.8)$ & $10(38.5)$ & 0.39 \\
\hline T2DM n (\%) & $7(10.6)$ & $8(30.8)$ & $0.020^{* * * *}$ \\
\hline \multicolumn{4}{|l|}{ Inflammatory Cytokines } \\
\hline TNF- $\alpha$ pg/mL & $775.07 \pm 80.36$ & $656.11 \pm 55.62$ & 0.90 \\
\hline $\mathrm{IL}-6 \mathrm{pg} / \mathrm{mL}$ & $595.06 \pm 122.85$ & $864.45 \pm 227.39$ & 0.75 \\
\hline \multicolumn{4}{|c|}{ Oxidative Damage to DNA and Repair } \\
\hline 8-OHdG ng/mL & $67.92 \pm 16.45$ & $|37.07 \pm 6| .79$ & 0.39 \\
\hline hOGGI ng/mL & $5.8 I \pm 0.92$ & $3.07 \pm 1.15$ & $0.032 * *$ \\
\hline \multicolumn{4}{|l|}{ Oxidants } \\
\hline LPO $\mu \mathrm{M}$ & $3.84 \pm 0.21$ & $3.90 \pm 0.22$ & 0.34 \\
\hline 8-Isoprostane $\mathrm{pg} / \mathrm{mL}$ & $21.70 \pm 1.02$ & $30.85 \pm 3.79$ & $0.039 * *$ \\
\hline Nitric oxide $\mu M$ & $234.67 \pm 7.58$ & $250.87 \pm 8.84$ & 0.42 \\
\hline \multicolumn{4}{|l|}{ Antioxidants } \\
\hline $\mathrm{SOD} \mathrm{U} / \mathrm{mL}$ & $0.36 \pm 0.03$ & $0.42 \pm 0.07$ & 0.75 \\
\hline GPx nmol/min/mL & $2.06 \pm 0.23$ & $2.09 \pm 0.18$ & 0.23 \\
\hline Total antioxidant capacity $\mathrm{mM}$ & $2.27 \pm 0.07$ & $2.31 \pm 0.13$ & 0.75 \\
\hline Catalase $\mathrm{mU} / \mathrm{mL}$ & $18.06 \pm 1.10$ & $17.26 \pm 1.73$ & 0.89 \\
\hline
\end{tabular}

Notes: Values are mean \pm SD, SEM or percentage. ${ }^{* * * *}$ Chi-square test, *Student's $t$-test, **Mann Whitney U-test.

Abbreviations: VAF, visceral abdominal fat; BMI, body mass index;T2DM, type 2 diabetes Mellitus; TNF, tumor necrosis factor alpha; IL-6, interleukin 6; 8-OHdG, 8-hydroxy-2'-deoxyguanosine; hOGGI, human oxoguanin glycosylase; LPO, Lipoperoxides; SOD, Superoxide dismutase; GPx, Glutathione peroxidase.

Table 4 Correlation Between the Visceral Abdominal Fat and Markers of Oxidative Stress in Overweight and Obesity

\begin{tabular}{|l|l|l|l|l|}
\hline & Age & VAF & WHR & BMI \\
\hline LPO & 0.072 & $0.274^{*}$ & $0.302^{*}$ & -0.185 \\
Total antioxidant capacity & -0.008 & -0.020 & $0.244^{*}$ & 0.092 \\
8-OHdG & $0.278^{*}$ & -0.042 & 0.239 & 0.024 \\
8-isoprostanes & 0.041 & $0.249^{*}$ & 0.085 & $0.261^{*}$ \\
\hline
\end{tabular}

Notes: Correlation was done using Spearman correlation test. $*_{p}<0.0 .5$.

Abbreviations: LPO, lipoperoxides; 8-OHdG, 8-hydroxy-2'-deoxyguanosine; VAF, visceral abdominal fat; WHR, waits-hip ratio; BMI, body mass index.

tomography to settle cutoff points of VAF in the Japanese population. ${ }^{27,28}$

More recently, different cutoff scores of VAF were established for men $\left(\geq 599 \mathrm{~cm}^{3}\right)$ and women $\left(\geq 399 \mathrm{~cm}^{3}\right)$ as a predictor for systolic blood pressure $\geq 130 \mathrm{mmHg}$ in healthy young European population using DEXA method. ${ }^{29}$ In our study, VAF volume values differ from those reported in
Japanese and European populations. In the available literature, we did not find previously standardized values of VAF in the world or Mexican population apart from those reported in the European and Japanese population. The prevalence of $\mathrm{BMI} \geq 30 \mathrm{~kg} / \mathrm{m}^{2}$ reported for Japanese (3.5\%) and European (36.5\%) people compared to Mexico may be the main reason for the differences in these findings. ${ }^{30,31}$

Lipid peroxidation is a process by which oxidants such as free radicals or non-radical species attack lipids with carbon-carbon double bonds. Malondialdehyde (MDA) is the main product of LPO. It is associated with increasing high levels of cholesterol and hypertension. ${ }^{32,33}$ It has been shown that MDA increases in obese patients compared to healthy people. ${ }^{34,35}$ In the present study, the levels of LPO among subjects with normal weight, overweight, and obesity were similar. This result could be related to the fact that dyslipidemia was homogeneously distributed between groups. Dyslipidemia is characterized by high 
serum levels of total and LDL cholesterol, and they positively correlate with LPO levels in obesity. ${ }^{36}$ Therefore, one might expect to find similar levels of MDA among the three groups studied because the prevalence of dyslipidemia was also similar. Abbasian et al reported a positive correlation between MDA with BMI and waist circumference. ${ }^{33}$ Xiao et al showed a positive correlation between LPO with BMI and VAF. ${ }^{18}$ Our findings add confirmation to the correlation of LPO between the volume of VAF and waist-hip ratio. 8-Isoprostanes can also represent the OS.

8-Isoprostanes is a family derived from the oxidation of arachidonic acid. 8-Isoprostanes can be measured in urine, serum, plasma, and other biological fluids and tissues. ${ }^{37,38} 8$-Isoprostanes are increased in obesity compared to healthy non-obese controls. ${ }^{39}$ There is evidence that 8-Isprostanes correlate negatively with HDL-C cholesterol. ${ }^{40}$ Urinary 8 -Iso-PGF ${ }_{2 \alpha}$ is positivity correlated to BMI and VAF area in obese subjects with or without metabolic syndrome. ${ }^{18,41}$

However, Sjogren et al found no correlation of 8-Iso$\mathrm{PGF}_{2 \mathrm{a}}$ with BMI. ${ }^{42}$ Our results showed no differences in levels of 8-Isoprostans between subjects of normal weight, overweight, and obesity. Contrary, we found a correlation between serum 8-Isoprostane and BMI. Subjects with high VAF volume showed an elevated concentration of 8-Isoprostane than normal VAF. In addition, 8-Isoprostane was positively correlated to VAF volume. These findings suggest that the OS represented by the serum concentration of LPO and 8-Isoprostanes is related to the accumulation of VAF.

NO is a free radical and has vasodilatory, antithrombotic, anti-proliferative, and anti-inflammatory effects in the vasculature. ${ }^{43}$ Under OS, NO reacts with the radical $\mathrm{O}_{2}{ }^{--}$to generate peroxynitrite $\left(\mathrm{ONOO}^{-}\right)$, causing damage to the endothelium. ${ }^{44}$ Controversial data is reported about NO behavior in obesity. NO is associated with increasing BMI, and it is related to metabolic disorders. $^{45,46}$ Some studies report that NO decreases in obesity. ${ }^{47}$ Our study found no differences in NO levels between normal weight, overweight, obesity, or high VAF. Similar results were reported by other authors who found no statistical differences in NO levels in obesity. ${ }^{48,49}$ Furthermore, it is described that the capacity of the endothelium to release NO under basal conditions is not compromised in overweight and obese adults. ${ }^{50}$

Adipocytes secrete TNF- $\alpha$ and IL- 6 , and their concentration is associated with the percentage and distribution of adipose tissue in the body. These cytokines are critical in the mechanisms for the induction of persistent inflammatory state production in obese subjects. ${ }^{51}$ In our study, we found similar levels of these two cytokines in subjects with normal weight, overweight, obesity, or high VAF. These data reflect similar sub-clinical inflammatory status within the subjects included in the study.

The oxidative DNA damage marker was increased in overweight and was higher in obesity almost three times (NS). It has been reported that obese people have DNA damage. Tursi Ríspoli et al, showed a significant increase in the marker of oxidative damage to DNA in obese patients compared to those of normal weight. However, it is essential to consider that the BMI reported by the author, was higher than that found in our study. ${ }^{52}$ Oxidative damage to DNA has mutagenic potential. Previous studies described the high concentration of oxidative DNA damage was related to obesity and tumorigenesis. These studies suggest that patients with high BMI have a significant risk of carcinogenesis. ${ }^{53,54}$

The existence of the DNA repair system is essential to overcome the damage and maintain the integrity of the DNA structure. There is reported that the induction of ROS in human cells participates in the inhibition of DNA repair by increasing protein oxidation. ${ }^{55}$ The hOGG1 enzyme is one of the most critical oxidative enzymes that repair DNA damage. The deficiency of this enzyme developed metabolic disorders such as low glucose tolerance, higher insulin levels, and liver steatosis. ${ }^{56}$ In our study, DNA repair enzyme levels were slightly lower in overweight and obese subjects than in normalweight subjects (NS). Nevertheless, a significant decrease was found in high VAF volume subjects. These findings could mean that VAF is a better indicator of oxidative DNA damage than BMI.

Antioxidant defense enzymes have been described in obesity. Furukawa et al show that mRNA expression of SOD, GPx, and catalase is reduced in obese-induced rats, ${ }^{41}$ whereas Vincent et al reported the opposite, an increase of these enzymes, also in a rat model. ${ }^{57}$

It has been previously reported that the activity of the antioxidant enzymes SOD, GPx, and catalase was reduced in obese children, adolescents, and adult women. There was even a negative correlation between SOD and GPx enzymes with BMI. ${ }^{58,59}$ However, another study did not report statistical differences in SOD, GPx, and catalase between high BMI $\left(>24 \mathrm{~kg} / \mathrm{m}^{2}\right)$ and low BMI $\left(<24 \mathrm{~kg} / \mathrm{m}^{2}\right) .{ }^{60}$ Also, an increase in TAC levels was previously reported in 
Table 5 Antioxidants Between Normal Weight vs Comorbidities Normal Weight, Overweight and Obese Subjects

\begin{tabular}{|l|l|l|l|l|l|}
\hline & Normal Weight (n II) & $\begin{array}{l}\text { Comorbidities } \\
\text { Normal Weight (n 12) }\end{array}$ & Overweight (n 36) & Obese (n 33) & p \\
\hline $\begin{array}{l}\text { SOD U/mL } \\
\text { GPx nmol/min/mL }\end{array}$ & $0.45 \pm 0.05$ & $0.54 \pm 0.06$ & $0.35 \pm 0.05^{\mathrm{a}, \mathrm{b}}$ & $0.34 \pm 0.06^{\mathrm{a}, \mathrm{b}}$ & $0.01^{*}$ \\
$0.15^{\mathrm{b}}$ & $1.67 \pm 0.21^{\mathrm{a}}$ & $2.41 \pm 0.33^{\mathrm{a}, \mathrm{b}}$ & $2.17 \pm 0.25^{\mathrm{a}, \mathrm{b}}$ & $0.003^{*}$ \\
\hline
\end{tabular}

Notes: Values are mean \pm SEM. Table 5 The table shows only the significant values between subjects of normal weight and normal weight with comorbidities. $*$ KruskalWallis test. "vs normal weight, ${ }^{b} v s$ comorbidities normal weight.

Abbreviations: SOD, superoxide dismutase; GPx, glutathione peroxidase;

overweight and obese subjects compared to the normal weight group. ${ }^{61}$

In the present study, we found a significant decrease in SOD activity and an increase in GPx in overweight and obese subjects compared to the normal weight group. We found a significant increase in TAC in overweight subjects compared to those of normal weight.

Our normal weight group includes subjects with T2DM, hypertension, and dyslipidemia. Therefore, we made a subgroup of normal weight without comorbidities (Table 5). We still found significant differences in the activity of SOD and GPx in overweight and obese subjects, compared with normal weight with or without comorbidities. However, Brown et al reported no differences in SOD activity and glutathione concentration in healthy normal weight and overweight and obese subjects. ${ }^{62}$

Some demographic characteristics may be linked to these different findings. An animal model study indicates that the increase in age may decrease the expression of Gpx. ${ }^{63}$ Gender characteristics could be another influential factor. However, in this study, both the value of age and the frequency of gender were distributed homogeneously among the normal weight, overweight, and obesity groups ( $p=0.32$, $p=0.73$, respectively). This distribution helps to discard these variables as confounding factors for this study.

The mayor clinical evidence available about the association between fat distribution, including VAF, and OS focus on markers of oxidative damage and its effects on mitochondrial activity processes. ${ }^{13,14,64}$ Little is the evidence related to antioxidant defenses. Heval et al reports that glutathione concentration correlates inversely with the amount of various fat deposits, such as gynoid fat, android fat, and total fat. ${ }^{65}$ Xiao et al reported that SOD correlated negatively with the VAF area. ${ }^{18}$ Nevertheless, we found no correlation between enzymatic antioxidants and VAF volume. Our findings indicate that the increase of VAF is associated with OS represented as an increase in oxidants markers, mostly lipoperoxidation. Besides, the activity of antioxidant enzymes may not have a significant role in this association.

Strengths. As far as we know, this is the first study that gives exploratory cutoff values of VAF volume for cardiometabolic risks as hypertension, T2DM, and dyslipidemia in the Mexican population. However, an improved cutoff of VAF volume for risk assessment is needed. As mentioned before, the available literature reviewed in this study reports that the association between OS and VAF is limited to lipoperoxidation markers. Accordingly, information related to other types of oxidative damage and the behavior of antioxidant defenses is still lacking. This study shows broader characteristics of the oxidative state with high VAF, which can help identify the specific OS mechanisms associated with VAF presented since overweight and obesity. This data could lead to the design of new longitudinal studies with a diagnostic or therapeutic approach.

Limitations of the study. A cross-sectional study was conducted with a limited number of subjects, and no causality between VAF and blood indicators can establish from this study design. The subjects included were predominantly women $(77 \%)$ and some men who spontaneously attended a medical review. The cutoff values for VAF volume were exploratory and obtained from the Mexican population by using the densitometer Lunar iDXA, GE Healthcare ${ }^{\circledR}$, and, therefore, may not be suitable to compare with other populations or methods. We emphasize that subjects with normal weight, overweight, and obesity were not healthy, they have hypertension, dyslipidemia, or T2DM, and these associated pathologies are capable of altering the results of the metabolites analyzed.

\section{Conclusion}

The OS markers LPO and 8-isoprostanes are correlated with VAF in obese or overweight subjects. Besides, subjects with high VAF show decreased hOGG1 concentration and a tendency to increased $8-\mathrm{OHdG}$. The activity of 
endogenous antioxidant enzymes (SOD, GPx) showed changes in overweight or obese subjects. However, these changes did not show to be associated with VAF. These findings suggest that the predominantly oxidative damage associated with VAF in overweight or obesity is lipoperoxidation and oxidative DNA damage. Further prospective studies are needed to establish the causality of VAF on OS.

\section{Funding}

1.1.4.8.6 Strengthening Research and Postgraduate Studies, 2017. Secretariat of Public Education, Mexico.

\section{Disclosure}

The authors declare that they have no conflicts of interest.

\section{References}

1. Serra L, Bautista I. Etiology of obesity: two "key issues" and other emerging factors. Nutr Hosp. 2013;28:32-43.

2. Barquera S, Campos I, Hearnandes L, et al. Obesity and central adiposity in Mexican adults: results from the Mexican national health and nutrition survey 2006. Salud Publica Mex. 2006;51:S595-S603.

3. DiBonaventura MD, Meincke H, Le Lay A, Fournier J, Bakker E, Ehrenreich A. Obesity in Mexico: prevalence, comorbidities, associations with patient outcomes, and treatment experiences. Diabetes Metab Syndr Obes. 2017;11:1-10. doi:10.2147/DMSO.S129247

4. Hotamisligil GS, Bernlohr DA. Metabolic functions of FABPsmechanisms and therapeutic implications. Nat Rev Endocrinol. 2015;11(10):592-605. doi:10.1038/nrendo.2015.122

5. Hotamisligil GS. Inflammation and metabolic disorders. Nat. 2006;444(7121):860-867. doi:10.1038/nature05485

6. Cnop M, Landchild MJ, Vidal J, et al. The concurrent accumulation of intra-abdominal and subcutaneous fat explains the association between insulin resistance and plasma leptin concentrations: distinct metabolic effects of two fat compartments. Diabetes. 2002;51 (4):1005-1015. doi:10.2337/diabetes.51.4.1005

7. Wagenknecht LE, Langefeld CD, Scherzinger AL, et al. Insulin sensitivity, insulin secretion, and abdominal fat: the insulin resistance atherosclerosis study (IRAS) family study. Diabetes. 2003;52 (10):2490-2496. doi:10.2337/diabetes.52.10.2490

8. Neeland IJ, Grundy SM, Li X, Adams-Huet B, Vega GL. Comparison of visceral fat mass measurement by dual-X-ray absorptiometry and magnetic resonance imaging in a multiethnic cohort: the dallas heart study. Nutr Diabetes. 2016;6(7):e221. doi:10.1038/nutd.2016.28

9. Kaul S, Rothney MP, Peters DM, et al. Dual-energy x-ray absorptiometry for quantification of visceral fat. Obesity. 2012;20(6):13 13-1318. doi:10.1038/oby.2011.393

10. Manna P, Jain SK. Obesity, oxidative stress, adipose tissue dysfunction, and the associated health risks: causes and therapeutic strategies. Metab Syndr Relat Disord. 2015;13(10):423-444. doi:10.1089/ met.2015.0095

11. McMurray F, Patten DA, Harper ME. Reactive oxygen species and oxidative stress in obesity-recent findings and empirical approaches. Obesity (Silver Spring). 2016;24(11):2301-2310. doi:10.1002/oby.21654

12. Ba X, Boldogh I. 8-Oxoguanine DNA glycosylase 1. Beyond repair of the oxidatively modified base lesions. Redox Biol. 2018;14:669-678. doi:10.1016/j.redox.2017.11.008

13. Fujita K, Nishizawa H, Funahashi T, Shimomura I, Shimabukuro M. Systemic oxidative stress is associated with visceral fat accumulation and the metabolic syndrome. Circ J. 2006;70(11):1437-1442. doi:10.1253/circj. 70.1437
14. Okauchi Y,K, Kishida K, Funahashi T, et al. Cross-sectional and longitudinal study of association between circulating thiobarbituric acid-reacting substance levels and clinic biochemical parameters in 1,178 middle-aged Japanese men - the Amagasaki visceral fat study. Nutr Metab (Lond). 2011;8(1):82. doi:10.1186/1743-7075-8-82

15. Pou KM, Massaro JM, Hoffmann U, et al. Visceral and subcutaneous adipose tissue volumes are cross-sectionally related to markers of inflammation and oxidative stress. the Framingham heart study. Circulation. 2007;116(11):1234-1241. doi:10.1161/CIRCULATIONAHA.107.710 509

16. Nimse SB, Pal D. Free radicals, natural antioxidants, and their reaction mechanisms. RSC Adv. 2015;5(35):27986-28006. doi:10.1039/ C4RA13315C

17. Higuchi M, Dusting GJ, Peshavariya $\mathrm{H}$, et al. Differentiation of human adipose-derived stem cells into fat involves reactive oxygen species and forkhead box O1 mediated upregulation of antioxidant enzymes. Stem Cells Dev. 2013;22(6):878-888. doi:10.1089/scd.20 12.0306

18. Xiao J, Lan L, Yi T, Rui W, Qiang L. The correlation between oxidative stress level and intra-abdominal fat in obese males. Medicine. 2019;98(7):e14469. doi:10.1097/MD.0000000000014469

19. World Health Organization. Waist circumference and waist-hip ratio. Report of a WHO expert consultation, Geneva 8-11 December 2008. World Health Organization: Geneva; 2011

20. WHO Study Group. Obesity: "preventing and managing the global epidemic. Report of a WHO consultation". World Health Organ Tech Rep Ser. 2000;894:1-253.

21. Carey RM, Whelton PK. 2017 ACC/AHA hypertension guideline writing committee. prevention, detection, evaluation, and management of high blood pressure in adults: synopsis of the 2017 American College of Cardiology/American Heart Association Hypertension guideline. Ann Intern Med. 2018;168(5):351-358. doi:10.7326/M17-3203

22. American Diabetes Association. Classification and diagnosis of diabetes:standards of medical care in diabetes-2019. Diabetes Care. 2019;42(Supplement 1):S13-S28. doi:10.2337/dc19-S002

23. National Institutes of Health ATP III. Guidelines at-a-glance quick desk reference. [Cited November 28, 2015.]. Available from: https:// www.nhlbi.nih.gov/files/docs/guidelines/atglance.pdf.

24. Wainson MG, Batterham AM, Tsakirides C, Rutherford ZH, Hind K. Prediction of whole-body fat percentage and visceral adipose tissue mass from five anthropometric variables. PLoS One. 2017;12(5): e 0177175. doi:10.1371/journal.pone. 0177175

25. Ng M, Fleming T, Robinson M, et al. Global, regional, and national prevalence of overweight and obesity in children and adults during 1980-2013: a systematic analysis for the global burden of disease study 2013. Lancet. 2014;384(9945):766-781. doi:10.1016/S01406736(14)60460-8

26. Rtveladze K, Marsh T, Barquera S, et al. Obesity prevalence in Mexico: impact on health and economic burden. Public Health Nutr. 2014;17(1):233-239. doi:10.1017/S1368980013000086

27. Kim JA, Choi CJ, Yum KS. Cut-off values of visceral fat area and waist circumference: diagnostic criteria for abdominal obesity in a Korean population. J Korean Med Sci. 2006;21(6):1048-1053. doi:10.3346/jkms.2006.21.6.1048

28. Tsukiyama H, Nagai Y, Matsubara F, et al. Proposed cut-off values of the waist circumference for metabolic syndrome based on visceral fat volume in a Japanese population. J Diabetes Investig. 2016;7 (4):587-593. doi:10.1111/jdi.12454

29. Miazgowski T, Kucharski R, Sołtysiak M, Taszarek A, Miazgowski B, Widecka K. Visceral fat reference values derived from healthy European men and women aged 20-30 years using GEhealthcare dual-energy x-ray absorptiometry. PLoS One. 2017;12 (7):e0180614. doi:10.1371/journal.pone.0180614

30. Tanaka H, Kokubo. Y. Epidemiology of obesity in Japan. JMAJ. 2005;48(1):34-41. 
31. Berghöfer A, Pischon T, Reinhold T, Apovian CM, Sharma AM, Willich SN. Obesity prevalence from a European perspective: a systematic review. BMC Public Health. 2008;8(1):200. doi:10.1186/1471-2458-8-200

32. Ayala A, Muñoz MF, Argüelles S. Lipid peroxidation: production, metabolism, and signaling mechanisms of malondialdehyde and 4-hydroxy-2-nonenal. Oxid Med Cell Longev. 2014;2014:360438. doi: $10.1155 / 2014 / 360438$

33. Abbasian M, Delvarianzadeh M, Ebrahimi H, Khosravi F, Nourozi P. Relationship between serum levels of oxidative stress and metabolic syndrome components. Diabetes Metab Syndr. 2018;12(4):497-500. doi:10.1016/j.dsx.2018.03.015

34. Adnan MT, Amin MN, Uddin G, et al. Increased concentration of serum MDA, decreased antioxidants and altered trace elements and macro-minerals are linked to obesity among Bangladeshi population. Diabetes Metab Syndr. 2019;13(2):933-938. doi:10.1016/j.dsx.20 18.12.022

35. Lechuga AM, Gallego D, Ruiz P, et al. Obesity induced alterations in redox homeostasis and oxidative stress are present from an early age. PLoS One. 2018;13(1):e0191547. doi:10.1371/journal.pone.0191547

36. Mutlu U, Oztezcan S, Telci A, et al. An increase in lipoprotein oxidation and endogenous lipid peroxides in serum of obese women. Clin Exp Med. 2003;2(4):171-174. doi:10.1007/s102380300002

37. Yoshida Y, Umeno A, Shichiri M. Lipid peroxidation biomarkers for evaluating oxidative stress and assessing antioxidant capacity in vivo. J Clin Biochem Nutr. 2013;52(1):9-16. doi:10.3164/jcbn.12-112

38. Czerska M, Zieliński M, Gromadzińska J. Isoprostanes - A novel major group of oxidative stress markers. Int J Occup Med Environ Health. 2015;29(2):179-190. doi:10.13075/ijomeh.1896.00596

39. Davì G, Guagnano MT, Ciabattoni G, et al. Platelet activation in obese women: role of inflammation and oxidant stress. JAMA. 2002;288(16):2008-2014. doi:10.1001/jama.288.16.2008

40. Nobécourt E, Jacqueminet S, Hansel B, et al. Defective antioxidative activity of small dense HDL3 particles in type 2 diabetes: relationship to elevated oxidative stress and hyperglycaemia. Diabetologia. 2005;48(3):529-538. doi:10.1007/s00125-004-1655-5

41. Furukawa S, Fujita T, Shimabukuro M, et al. Increased oxidative stress in obesity and its impact on metabolic syndrome. J Clin Invest. 2004;114(12):1752-1761. doi:10.1172/JCI21625

42. Sjogren P, Basu S, Rosell M, et al. Measures of oxidized low-density lipoprotein and oxidative stress are not related and not elevated in otherwise healthy men with the metabolic syndrome. Arterioscler Thromb Vasc Biol. 2005;25(12):2580-2586. doi:10.1161/01.ATV.00 00190675.08857.3d

43. Atawia RT, Bunch KL, Toque HA, Caldwell RB, Caldwell RW. Mechanisms of obesity-induced metabolic and vascular dysfunctions. Front Biosci (Landmark Ed). 2019;24(5):890-934. doi: $10.2741 / 4758$

44. Douki T, Cadet J. Peroxynitrite mediated oxidation of purine bases of nucleosides and isolated DNA. Free Radic Res. 1996;24(5):369-380. doi:10.3109/10715769609088035

45. Choi JW, Pai SH, Kim SK, Ito M, Park CS, Cha YN. Increases in nitric oxide concentrations correlate strongly with body fat in obese humans. Clin Chem. 2001;47(6):1106-1109. doi:10.1093/clinchem/ 47.6.1106

46. Zahedi S, Ghasemi A, Azizi F. Serum nitric oxide metabolites in subjects with metabolic syndrome. Clin Biochem. 2008;41(1617):1342-1347. doi:10.1016/j.clinbiochem.2008.08.076

47. Gruber HJ, Mayer C, Mangge H, Fauler G, Grandits N, Wilders M. Obesity reduces the bioavailability of nitric oxide in juveniles. Int J Obes (Lond). 2008;32(5):826-831. doi:10.1038/sj.ijo.0803795

48. Ferlito S, Gallina M. Nitrite plasma levels in type 1 and 2 diabetics with and without complications. Minerva Endocrinol. 1999;24 (3-4):117-121.
49. Klisic A, Kocic G, Kavaric N, Pavlovic R, Soldatovic I, Ninic A. Nitric oxide products are not associated with metabolic syndrome. J Med Biochem. 2019;38(3):361-367. doi:10.2478/jomb-2018-0035

50. DeSouza CA, Van Guilder GP, Greiner JJ, Smith DT, Hoetzer GL, Stauffer BL. Basal endothelial nitric oxide release is preserved in overweight and obese adults. Obes Res. 2005;13(8):1303-1306. doi:10.1038/oby.2005.157

51. Popko K, Gorska E, Stelmaszczyk-Emmel A, et al. Proinflammatory cytokines Il- 6 and TNF- $\alpha$ and the development of inflammation in obese subjects. Eur J Med Res. 2010;15(S2):120-122. doi:10.1186/ 2047-783X-15-S2-120

52. De Tursi L, Vázquez A, Vázquez A, Sáez G, Alí A, Gumbau V. Estrés oxidativo; estudio comparativo entre un grupo de población normal y un grupo de población obesa mórbida. Nutr Hosp. 2013;28 (3):671-675. doi:10.3305/nh.2013.28.3.6355

53. Cerdá C, Sánchez C, Climent B, et al. Oxidative stress and DNA damage in obesity-related tumorigenesis. Adv Exp Med Biol. 2014;824:5-17.

54. Irigaray P, Belpomme D. Basic properties and molecular mechanisms of exogenous chemical carcinogens. Carcinogenesis. 2010;31 (2):135-148. doi:10.1093/carcin/bgp252

55. McAdam E, Brem R, Karran P. Oxidative stress-induced protein damage inhibits DNA repair and determines mutation risk and therapeutic efficacy. Mol Cancer Res. 2016;14(7):612-622. doi:10.1158/ 1541-7786.MCR-16-0053

56. Sampath H, Vartanian V, Rollins MR, Sakumi K, Nakabeppu Y, Lloyd RS. 8-oxoguanine DNA glycosylase (OGG1) deficiency increases susceptibility to obesity and metabolic dysfunction. PLoS One. 2012;7(12):e51697. doi:10.1371/journal.pone.0051697

57. Vincent HK, Powers SK, Stewart DJ, Shanely RA, Demirel H, Naito H. Obesity is associated with increased myocardial oxidative stress. Int $J$ Obes Relat Metab Disord. 1999;23(1):67-74. doi:10.1038/sj.ijo.0800761

58. Habib SA, Saad EA, Elsharkawy AA, Attia ZR. Pro-inflammatory adipocytokines, oxidative stress, insulin, $\mathrm{Zn}$ and $\mathrm{Cu}$ : interrelations with obesity in Egyptian non-diabetic obese children and adolescents. Adv Med Sci. 2015;60(2):179-185. doi:10.1016/j.advms.2015.02.002

59. Amirkhizi F, Siassi F, Minaie S, Djalali M, Rahimi A, Chamari M. Is obesity associated with increased plasma lipid peroxidation and oxidative stress in women? ARYA Atheroscler. 2010;2:189-192.

60. An H, Du X, Huang X, et al. Obesity, altered oxidative stress, and clinical correlates in chronic schizophrenia patients. Transl Psychiatry. 2018;8(1):258. doi:10.1038/s41398-018-0303-7

61. Cruz S, Durán HH, Navarro M, Xochihua I, De la Peña S, Arroyo OE. Body mass index is associated with interleukin-1, adiponectin, oxidative stress and ioduria levels in healthy adults. Nutr Hosp. 2018;35(4):841-846. doi:10.20960/nh.1614

62. Brown LA, Kerr CJ, Whiting P, Finer N, McEneny J, Ashton T. Oxidant stress in healthy normal-weight, overweight, and obese individuals. Obesity (Silver Spring). 2009;17(3):460-466. doi:10.10 38/oby.2008.590

63. Pulliam DA, Liu Y, Salmon AB. Dynamic differences in oxidative stress and the regulation of metabolism with age in visceral versus subcutaneous adipose. Redox Biol. 2015;6:401-408. doi:10.1016/j. redox.2015.07.014

64. Ngo DTM, Sverdlov AL, Karki S, et al. Oxidative modifications of mitochondrial complex II are associated with insulin resistance of visceral fat in obesity. Am J Physiol Endocrinol Metab. 2019;316(2): E168-E77. doi:10.1152/ajpendo.00227.2018

65. Kelli HM, Corrigan FE 3rd, Heinl RE, et al. Relation of changes in body fat distribution to oxidative stress. Am J Cardiol. 2017;120 (12):2289-2293. doi:10.1016/j.amjcard.2017.08.053 


\section{Publish your work in this journal}

Diabetes, Metabolic Syndrome and Obesity: Targets and Therapy is an international, peer-reviewed open-access journal committed to the rapid publication of the latest laboratory and clinical findings in the fields of diabetes, metabolic syndrome and obesity research. Original research, review, case reports, hypothesis formation, expert opinion and commentaries are all considered for publication. The manuscript management system is completely online and includes a very quick and fair peer-review system, which is all easy to use. Visit $\mathrm{http}: / /$ www.dovepress.com/testimonials.php to read real quotes from published authors. 